\title{
Antoine Volodine, fictions du politique. Textes réunis et présentés par Anne Roche
}

\section{Emanuele Kanceff}

\section{Q OpenEdition}

1 Journals

\section{Edizione digitale}

URL: https://journals.openedition.org/studifrancesi/46297

DOI: 10.4000/studifrancesi.46297

ISSN: 2421-5856

\section{Editore}

Rosenberg \& Sellier

\section{Edizione cartacea}

Data di pubblicazione: 1 octobre 2007

Paginazione: 477-478

ISSN: 0039-2944

\section{Notizia bibliografica digitale}

Emanuele Kanceff, «Antoine Volodine, fictions du politique. Textes réunis et présentés par Anne Roche», Studi Francesi [Online], 152 (LI | II) | 2007, online dal 30 novembre 2015, consultato il 24 novembre 2021. URL: http://journals.openedition.org/studifrancesi/46297 ; DOI: https://doi.org/10.4000/ studifrancesi.46297

Questo documento è stato generato automaticamente il 24 novembre 2021.

\section{(c)}

Studi Francesi è distribuita con Licenza Creative Commons Attribuzione - Non commerciale - Non opere derivate 4.0 Internazionale. 


\title{
Antoine Volodine, fictions du politique. Textes réunis et présentés par Anne Roche
}

\author{
Emanuele Kanceff
}

\section{NOTIZIA}

AA. VV., «Écritures contemporaines», 8. Antoine Volodine, fictions du politique. Textes réunis et présentés par Anne ROCHE en collaboration avec Dominique VIART, avec un entretien d'Antoine Volodine, Caen, Lettres Modernes Minard, 2006 (Coll. "La Revue des lettres modernes"), pp. 277.

1 Per un autore così "giovane" (sa fa per dire: è nato nel 1950) e non ancora "consacrato" dalla critica, sia pure di successo e con una carriera già folta di opere, traduzioni, realizzazioni varie alle spalle, è lecito domandarsi quale sia attualmente la sua ricezione in Francia e altrove. A partire dagli anni Ottanta, la sua opera non ha fatto che arricchirsi a ritmo accelerato e guadagnare nuovi lettori. Oggetto delle attenzioni degli specialisti, nel 1999, con il premio Livre Inter e il premio Wepler ha suscitato nuove curiosità nel pubblico, mentre la sua opera era bersaglio di articoli di livello universitario e, nel 2003, di una tesi di dottorato.

Ora, a contribuire alla sua consacrazione a livello accademico, giunge questo numero di «Écritures contemporaines», la serie diretta da Dominique VIART presso la Revue des lettres modernes, che offre sull'autore "post-exotique" una folta e originale sequenza di studi, che certo contribuiranno alla sua migliore conoscenza e a un più deciso avviamento della riflessione critica che lo scrittore merita. Dal molto ricco volume, pieno di suggestioni che si desidererebbe seguire una a una, emerge comunque la figura di un artista dalle molteplici e originalissime modalità creative, in cui non sono assenti il delirio, la schizofrenia, la ricreazione della temporalità, ma anche labirintiche illusioni, figure dell'onirismo, orchestrazioni di identità, di spazi, di testi, curiose e 
significative intertestualità, teatralità senza limiti che vanno dal circo all'opera lirica e che ben si concretano nelle sue creazioni radiofoniche o nelle "vociferazioni" per strumenti e voci, che non sono eredità surrealiste ma effetto di una personale interpretazione del rigore musicale. Per questo non è né facile né evidente poter situare Volodine in una filière poetica o in una "scuola", individuare la sua costellazione storica, culturale e intellettuale, scopo peraltro della presente silloge di letture critiche. 